\title{
THE EFFECT OF TRIPLE-JUMP EXAMINATION (TJE)- BASED ASSESSMENT ON CLINICAL REASONING OF NURSING INTERNS IN ZABOL DURING 2017-2018
}

\author{
Mahdehi Poodineh Moghadam¹, Gholamhossein Mahmoudirad². Elham Shahraki Moghadam³ ${ }^{3}$ Hosien Shahdadi ${ }^{4}$, Habibollah Ismaili ${ }^{5}$
}

${ }_{1}^{1}$ Ph.D Student of Nursing, Faculty of Nursing and Midwifery, Birjand University of Medical Sciences, Birjand, Iran.

${ }^{2}$ Associate Professor of Nursing, Faculty of Nursing and Midwifery, Birjand University of Medical Sciences, Birjand, Iran.

${ }^{3}$ Nursing Department, Faculty of Nursing and Midwifery, Zabol University of Medical Sciences, Zabol, Iran.

${ }^{4}$ Assistant Professor, Faculty of Nursing and Midwifery, Zabol University of Medical Sciences, Zabol, Iran.

${ }^{5}$ Associate professor of Biostatistics, Faculty of Nursing and Midwifery, Birjand University of Medical Sciences, Birjand, Iran.

\section{ABSTRACT}

\section{BACKGROUND}

Assessment is the most fundamental part of any curriculum, because it can help identify and resolve the weaknesses of the curriculum. Evidence shows that to accurately evaluate the clinical reasoning as one of the essential skills of nursing students in diagnosing and solving clinical problems of patients, it is better to use problem-based assessment methods. We wanted to determine the effect of triple-jump examination (TJE) based assessment on the clinical reasoning of nursing interns in 2017.

\section{METHODS}

In this quasi experimental study, all nursing interns were selected based on the census sampling and randomly divided into two groups- control $(n=20)$ and experimental $(n=20)$. First, routine assessment was carried out in both groups. After completing the internship course in the respiratory ward, the assessment was carried out using TJE method in the experimental group and routine method in the control group. TJE-based assessment included three stages of presenting clinical scenarios to students, allocating time to studying and searching in electronic resources, and finally responding to clinical scenario questions. Clinical scenarios of common respiratory diseases such as tuberculosis, pneumonia and emphysema were designed based on library studies, and validity and reliability of these scenarios were also approved by experts. The overall score of the test was 0-20. Data analysis was carried out using SPSS ver. 23 and independent t-test, paired t-test, Wilcoxon, chi square test, and Chi-square tests.

\section{RESULTS}

The mean \pm standard deviation (SD) of the clinical reasoning score of the experimental group was $12.97 \pm 1.09$ before the intervention, which increased to $14.57 \pm 1.35$ after intervention and were statistically significant $(\mathrm{p}<0.001)$. Mean \pm SD of the clinical reasoning score of the control group increased from $12 \pm 1.24$ to $12.50 \pm 1.20$, and was also reported to be statistically significant $(\mathrm{p}=0.001)$. The change in the clinical reasoning mean score in the experimental group $(1.60 \pm 1.01)$ was more than the control group $(0.57 \pm 0.51)$, which was statistically significant $(\mathrm{p}<0.001)$.

\section{CONCLUSIONS}

The results showed that TJE-based assessment is a suitable method for assessing the clinical reasoning skills of nursing students; it also increases students' level of satisfaction. Therefore, the inclusion of such new method in clinical assessment programs is recommended to improve clinical skills of nursing students.

\section{KEY WORDS}

Clinical Assessment, Triple-Jump Examination, Clinical Nursing Reasoning

HOW TO CITE THIS ARTICLE: Moghadam MP, Mahmoudirad G, Moghadam ES, et al. The effect of triple-jump examination (TJE)based assessment on clinical reasoning of nursing interns in Zabol during 2017-2018. J. Evolution Med. Dent. Sci. 2019;8(30):24332438, DOI: $10.14260 /$ jemds/2019/530

\section{BACKGROUND}

One of the important pillars of nursing education system is clinical education. Clinical education is a process in which students gain clinical experiences while dealing with patients' clinical problems $(1)$ and is considered as the core of professional education, since it accounts for about half of the time allocated for nursing education programs. $(2,3)$

'Financial or Other Competing Interest': None.

Submission 21-05-2019, Peer Review 09-07-2019,

Acceptance 15-07-2019, Published 29-07-2019.

Corresponding Author:

Elham Shahraki Moghadam,

Nursing Department,

Faculty of Nursing and Midwifery,

Zabol University of Medical Sciences, Zabol, Iran.

E-mail: hadismast@gmail.com

DOI: $10.14260 /$ jemds $/ 2019 / 530$

Internships play a significant role in shaping the basic skills and professional abilities of nursing students.(4) Clinical education refers to activities facilitating learning in the clinical setting, in which the educator and the student are equally involved and its aim is to make measurable changes in students while performing clinical care. In fact, effective clinical education refers to the training and guidance provided by the educator in a situation with an appropriate curriculum, while the student takes care of the patient directly, and practically applies the concepts learned in the form of a curriculum while interacting with the educator and the environment.(5) Clinical education is affected by various factors and variables such as curriculum, instructor, learner, and educational environment, and it makes it difficult to judge students' clinical skills. Assessment is the key element in each curriculum.(6) Assessment is considered as a major step in the education process and weaknesses and strengths of the educational process are identified based on the results 
obtained, and it is possible to take a proper step towards reforming and transforming of the education system by removing educational failures. On the other hand, ineffective assessment can lead to poor professional skills of graduates and a reduction in the quality of medical care.(7) The curriculum and assessment complement each other in the education process. The role of assessment is to monitor the behavioural changes of learners in particular and monitor the effectiveness of other elements of nursing education.(8) Despite the importance of assessment, especially clinical assessment, this issue remains a mental, time-consuming, and often confusing problem, and most of the instructors and students are not satisfied with the clinical assessment procedure.(9) According to the results of Hadizadeh et al., $41 \%$ of nursing and midwifery students described the quality of clinical assessment at a poor level. (10) In another study, students stated that assessment tools do not pay much attention to their functional skills.(11) According to the results of a study by Farokhi et al. (2002), nursing and midwifery students in Mashhad referred to the lack of control of the work of each student, giving unrealistic grades to students, the lack of student participation in the assessment, the compositionbased and multiple-choice assessment, and the lack of assessment based on the educational goals as the common errors of clinical assessment.(12) Although there are various clinical assessment methods, evidence suggests that evaluating students' clinical skills requires accurate assessment of practical skills, and an effective step in improving its implementation can be taken by examining the views and experiences of members involved.(13,14) From the viewpoint of students and professors, the clinical assessment, which is completed based on a general form and is relied on the instructor's personal opinion and without a specific framework lacks enough competence to assess the clinical performance of students. Therefore, there is a need to use a suitable clinical assessment method that more accurately evaluates clinical performance of students.(15) Results of previous studies in nursing faculties of south states of the United States showed that $45 \%, 35 \%, 17 \%$, and $3 \%$ of the faculties didn't adopt any reconsideration in their clinical assessment methods for 5, 10-11, 11-15, and more than 15 years, respectively.(16) In recent years, there has been a serious interest in the revision of current clinical assessment methods and the use of active and student-oriented strategies that measure the skills and abilities of learners.(17) Clinical assessment methods include several ones such as portfolio, written report of the student's performance, logbook, and observational methods, often associated with students' dissatisfaction.(7) Another assessment method used in the clinical setting is the triple jump examination (TJE). TJE is an assessment method that evaluates the clinical problemsolving knowledge and skills of learners. This assessment method can be mainly used in problem-solving, learner-based, and self-learning curriculum.(18-20) Considering that problembased learning and self-regulation play a special role in medical science education, TJE is used in these teaching methods to evaluate learners and the problem that is examined as the test content is often related to the patient's clinical condition or the health issues of the clients.(18-22) If educator administrators can carry out clinical assessment on learners using problem-oriented practices, then graduates will be well-qualified and expert professionals that is expected by the community expects from medical science graduates.(23) Clinical nursing reasoning is one of the key features of professional clinical practice and one of the most important competencies required for safe patient care and proper and timely clinical decision-making.(24) Clinical reasoning is the logical process of collecting key information points, understanding patient problems and situations, planning and implementing, and evaluating interventions, and giving feedbacks during the learning process.(23) Clinical nursing reasoning can be defined by the cognitive process and the strategies used to understand information, identify, and diagnose patient problems. Clinical reasoning is a clinical way of thinking about clinical skills. (25,26) Identifying relevant key points is the foundation of clinical reasoning and attempts should be made to help a nursing student understand how to obtain relevant key information. A nurse must be competent in many cases of clinical reasoning, such as psycho-motor skills and physical examinations.(27) Clinical reasoning also leads to proper nursing diagnoses, clinical decision-making, problemsolving, independent nursing interventions, and improved patient care quality. (28) Nurses with poor clinical reasoning will not succeed in identifying patients, diagnosing their conditions, and saving their lives. ${ }^{(27,29)}$ The theory-practice gap in nursing leads to a discrepancy between the material taught and practical skills 0 . Today, given the complex clinical conditions of and the use of advanced technologies, nurses should more than ever be able to analyse clinical situations and make proper and timely decisions to provide quality care (). To ensure that graduate nurses can meet these expectations, nursing professors should use effective methods for teaching and evaluating students' clinical reasoning skills.(30) Despite the high validity of the TJE test in evaluating clinical reasoning, it has not yet been used in the clinical assessment of nursing students. Therefore, considering the consequences of superficial reasoning and incorrect decisions on the patients' clinical conditions, we decided to carry out a study to determine the effect of TJE-based assessment on the clinical reasoning of nursing interns in 2017.

\section{METHODS}

The present study is a quasi-experimental study with twogroup pre-test - post-test design. The study population consisted of nursing interns in Zabol Nursing and Midwifery Faculty. The census sampling method was used in this study. After obtaining permission from the Ethics Committee of Zabol University of Medical Sciences and observing the ethical codes approved, including informed participation in the study and confidentiality of personal information, all nursing interns were randomly assigned (toss a coin) to control $(n=20)$ and experimental groups $(n=20)$. The data collection tool was composed of two parts: demographic characteristics and the clinical reasoning questionnaire. In this study, the clinical reasoning of the two groups was assessed by scenarios designed based on the history of respiratory patients in two stages; namely, before and after the intervention. Accordingly, researcher-made clinical reasoning decision-making cards were used. Therefore, a clinical scenario related to the patient's clinical condition was prepared and related nursing diagnoses and care measures should be written by the student. 


\begin{tabular}{|c|c|c|c|}
\hline & \multicolumn{2}{|c|}{ Mean \pm SD } & \multirow[b]{2}{*}{$\begin{array}{l}\text { Results of Mann-Whitney } \\
\text { and Independent T Tests }\end{array}$} \\
\hline & $\begin{array}{c}\text { Experimental } \\
\text { Group }\end{array}$ & $\begin{array}{c}\text { Control } \\
\text { Group }\end{array}$ & \\
\hline Age & $22 / 45 \pm 2 / 35$ & $22 / 40 \pm 2 / 50$ & $P=0 / 330 \mathrm{Z}=0 / 974$ \\
\hline $\begin{array}{c}\text { Total } \\
\text { average }\end{array}$ & $15 / 89 \pm 1 / 37$ & $15 / 73 \pm 1 / 25$ & $\begin{array}{c}\mathrm{P}=0 / 698 \\
\mathrm{df}=38 \\
\mathrm{t}=0 / 391\end{array}$ \\
\hline
\end{tabular}

\begin{tabular}{|c|c|c|c|c|c|c|}
\hline \multirow{2}{*}{\multicolumn{2}{|c|}{ Variable }} & \multicolumn{2}{|c|}{ Experimental } & \multicolumn{2}{|c|}{ Control } & \multirow{2}{*}{$\begin{array}{c}\text { Chi-Square } \\
\text { Test }\end{array}$} \\
\hline & & Number & $\%$ & Number & $\%$ & \\
\hline \multirow[b]{2}{*}{ Gender } & Male & 9 & 45 & 8 & 40 & \multirow{2}{*}{$\begin{array}{c}\mathrm{P}=0 / 749 \\
\mathrm{df}=1 \\
\mathrm{X}^{2}=0 / 102\end{array}$} \\
\hline & Female & 11 & 55 & 12 & 60 & \\
\hline \multirow{2}{*}{$\begin{array}{l}\text { Having } \\
\text { interest in } \\
\text { nursing }\end{array}$} & Yes & 16 & 80 & 17 & 85 & \multirow{2}{*}{$\begin{array}{c}\mathrm{P}=0 / 677 \\
\mathrm{df}=1 \\
\mathrm{X}^{2}=0 / 173\end{array}$} \\
\hline & No & 4 & 20 & 3 & 15 & \\
\hline
\end{tabular}

Table 2. Frequency Distribution of Nursing Students Studied by Gender and Interest in Nursing in Experimental and Control Groups

\begin{tabular}{|c|c|c|c|c|c|}
\hline $\begin{array}{c}\text { Clinical Decision } \\
\text { Making (Score) }\end{array}$ & \multicolumn{2}{|c|}{ Experimental } & \multicolumn{2}{c|}{ Control } & $\begin{array}{c}\text { The Results of } \\
\text { Independent } \\
\text { T-Test }\end{array}$ \\
\hline $\begin{array}{c}\text { Before the } \\
\text { intervention }\end{array}$ & $12 / 97 \pm 1 / 09$ & 20 & $12 \pm 1 / 24$ & 20 & $\begin{array}{c}\mathrm{P}=0 / 71, \mathrm{df}=38, \\
\mathrm{~T}=0.29\end{array}$ \\
\hline $\begin{array}{c}\text { After the } \\
\text { intervention }\end{array}$ & $14 / 57 \pm 1 / 35$ & 20 & $12 / 50 \pm 1 / 20$ & 20 & $\begin{array}{c}\mathrm{P}<0 / 001, \mathrm{df}=38, \\
\mathrm{~T}=5.13\end{array}$ \\
\hline $\begin{array}{c}\text { The result of paired } \\
\text { T-test }\end{array}$ & $\begin{array}{c}\mathrm{P}<0 / 001 \\
\mathrm{df}=19 \\
\mathrm{t}=7 / 032\end{array}$ & & $\begin{array}{c}\mathrm{P}=0 / 001 \\
\mathrm{df}=19 \\
\mathrm{t}=3 / 82\end{array}$ & & \\
\hline Table 3. Mean \pm SD of Nursing Student's Clinical Reasoning Score in \\
Two Groups Before and After Intervention
\end{tabular}

\begin{tabular}{|c|c|c|c|c|c|}
\hline & $\begin{array}{c}\text { Experimental } \\
\text { Group }\end{array}$ & $\begin{array}{c}\text { Control } \\
\text { Group }\end{array}$ & \multicolumn{2}{|c|}{ T-Test Statistic } \\
\cline { 2 - 3 } & Mean \pm SD & Mean \pm SD & df & t \\
\hline $\begin{array}{c}\text { Changes in the mean } \\
\text { score of clinical } \\
\text { reasoning }\end{array}$ & $1 / 60 \pm 1 / 01$ & $0 / 57 \pm 0 / 51$ & $\mathrm{p}<0 / 001$ & 38 & $4 / 01$ \\
\hline
\end{tabular}

Table 4. Difference in The Mean Scores of Nursing Student's Clinical Reasoning after Intervention in the Experimental and Control Groups

\begin{tabular}{|c|c|c|}
\hline Satisfaction with the Assessment Method & Number & Percentage \\
\hline Low & 2 & 10 \\
\hline Moderate & 5 & 25 \\
\hline High & 13 & 65 \\
\hline Total & 20 & 100 \\
\hline Table 5. Frequency Distribution of Nursing Students Studied Based on \\
Their Satisfaction with JTE-Based Assessment Method in The \\
Experimental Group \\
\hline
\end{tabular}

The purpose of designing such scenarios was not solely to identify the diagnosis of the defined patient, but the students were asked to answer the questions presented at the end of each scenario according to the signs and symptoms presented in the scenarios and to raise nursing diagnosis and measures. Clinical scenarios were developed based on common respiratory symptoms, including pneumonia, tuberculosis, and emphysema. According to the educational objectives, important points were given to the students in both groups regarding the care of patients with respiratory diseases during the internship. In both groups before starting internship in the internal respiratory wards,

Clinical reasoning was evaluated using the mentioned scenarios and, the assessment was carried out in the experimental and control groups using TJE and routine methods, respectively after the completion of such internship. The intervention method in the experimental group was that clinical scenarios were provided to the students without any questions for 5 minutes and then were taken back from them in the first stage. In the second stage, they were given an opportunity to carry out independent library studies for 20 minutes. Then in the third stage, the same scenarios and questions related to each scenario were again provided to the students, and 45 minutes were allocated to them to analyse the clinical situations and answer the questions. The total score range was between $0-20$. Clinical reasoning questionnaire was developed by nursing faculty instructors based on nursing internal respiratory surgery books and its validity was confirmed by 10 faculty members and respiratory specialists. Cronbach's alpha method was used to determine the reliability of the questionnaire and its reliability was confirmed with $\alpha=$ 0.87. Data analysis was carried out using SPSS ver. 23. The Shapiro-Wilk test was used to determine the normal distribution of quantitative variables and descriptive statistics (mean, standard deviation, and frequency distribution) were used to describe demographic characteristics. In order to compare the mean score of clinical reasoning before and after intervention, paired t-test was used, and independent t-test and chi square test were used were also used to make intergroup comparison. The significance level was considered as $\mathrm{P}<0.05$.

\section{RESULTS}

The total number of research subjects was 40 individuals who were randomly assigned to two groups of experimental and control. The mean age of the students in the experimental and control groups was $22.45 \pm 2.35$ and $22.40 \pm 2.50$ years, respectively. The mean of the total average of students in the experimental and control groups was also $15.89 \pm 1.37$ and $15.73 \pm 1.25$, respectively. It should be noted that there is no statistically significant difference between the two groups in terms of demographic variables (Tables 1 and 2).

The results of the present study showed that the preintervention mean score of the students' clinical reasoning did not differ significantly between the two groups $(\mathrm{P}=0.71)$ and the results of the paired t-test also revealed that postintervention mean score of the students' clinical reasoning was statistically significant in both groups $(\mathrm{P}<0.001)$ (Table 3). In order to compare the effect of two methods of evaluating clinical reasoning, i.e. JTE and routine methods, the difference between the mean score of clinical reasoning was used in pre-test and post-test stages, so that the difference between the mean clinical reasoning scores in both pre-test and post-stages was higher in the experimental group than the control group, and was statistically significant (Table 4).

According to Table 5, 65\% of the students of the experimental group had high satisfaction with this method and believed that the application of this method was innovative and excellent and an effective learning and assessment method. A total of $25 \%$ of the participants also expressed moderate satisfaction, and only $10 \%$ of students reported low satisfaction.

\section{DISCUSSION}

The aim of this study was to determine the effect of JTE-based assessment of the clinical reasoning of nursing interns. Based on the findings of this study, the mean clinical reasoning score in the experimental group which was evaluated using the JTE method improved from $12.97 \pm 1.09$ to $14.57 \pm 1.35$. In both groups, the clinical reasoning mean score increased after intervention and was statistically significant, but the mean change in the mean score of clinical reasoning in the experimental group was greater than that in the control group, 
showing 2.5 times higher change in the experimental group than the control group, which was statistically significant. Since there was no study similar to the present study, we compared the results of this study with similar studies that examined the impact of portfolio and Mini-CEX-Dops-Osce methods on clinical skills, as JTE test, as the methods mentioned above, is part of the new assessment methods. On the other hand, nurses' clinical reasoning can be considered as a cognitive process and strategies for understanding patients' information, identifying and diagnosing their problems, as well as a clinical way of thinking about clinical skills, $(25,26)$ therefore, the result of the present study can be compared with studies on other clinical skills. Consistent with the results of the present study, Habibi showed that the mean of final assessment scores in the experimental group (DOPS and MiniCEX methods) was significantly higher than that of the control group (routine method) and the two methods of Dops and Mini- Cex Has promoted the clinical skills of nursing students.(31) Salehi et al. conducted a study to determine the effect of peer education on the clinical skills of nursing students (interns and apprentice). In this semi-experimental study, 71 nursing interns and 84 apprentices were randomly divided into intervention and control groups. The results of this study showed that the mean \pm SD of nursing interns' clinical skills in the intervention and control groups was 39.18 \pm 0.68 and $32.3 \pm 23.77$, respectively. The mean \pm SD of nursing apprentice's clinical skills in the intervention and control groups was also $36.9 \pm 2.45$ and $32.73 \pm 4.40$, respectively. (32) Therefore, the use of this new educational method has been effective in improving the clinical performance of nursing students, which is consistent with the results of the present study. Consistent with the present study, Hekmatpou conducted a study entitled "the effect of portfolio method on

the accuracy of clinical assessment of nursing interns" in Arak University of Medical Sciences. In this study, students were evaluated by a instructor and based on the nursing college's routine assessment sheet after the first two weeks of internship in the internal ward and management, and by a researcher-fellow, based on a portfolio assessment sheet in the last two weeks. The results showed a three-score difference between the average scores given by the instructors to the students in the internship in the management field using the routine method (19.4) and the average scores given by portfolio method (16.5) as well as a a three-score difference between the average scores given by the instructor to the student interns the internal ward using the routine method. (19.11) and mean scores given by the portfolio method (16.3). On the other hand, there was a significant difference between the mean scores obtained using portfolio and routine methods in terms of students' viewpoints on effective clinical learning of the field internship in the internal and management wards.(33) The score obtained from assessment methods such as portfolio and TJE methods is more realistic than traditional ones, because it is based on written evidence; it also enhances learners' satisfaction. Sadeghi \& Shahabi Nejad evaluated nursing students using the OSCE method and reported that the total score of students' performance in the procedures examined was $132.38 \pm 19.17$ and the total score of knowledge of $18.23 \pm 3.71$ out of 32 and the students' knowledge and performance were at the moderate level, which is consistent with the present study.(34) The results of this study, consistent with the present study, showed that clinical assessment of students based on a reliable and objective method can lead to the movement of educational programs towards new methods to improve the quality of education. In the present study, $65 \%$ of interns had a high degree of satisfaction with this assessment method and $25 \%$ of expressed moderate satisfaction, which is recommended this method more frequently considering the importance of new assessment methods, as, in the study of Hekmatpou, more than $80 \%$ of students fully agreed with effective portfolio learning during internship at the internal field and nursing management.(33) So, it is possible to create satisfaction in students by proper diagnosis of students' clinical skills using objective methods of clinical assessment as compared to other conventional ones. It is worth mentioning that in the present study, only $10 \%$ of the students had a low degree of satisfaction with this method and attributed such low satisfaction to lack of familiarity with this method, and the failure to implement such method in a routine manner, the time limit of the study, and the similarity of the symptoms of the respiratory disease. Consistent with the results of the present study, Bolourchi et al. in a study aimed at comparing the satisfaction of nursing students with two methods of the objective structured clinical examination (OSCE) and practical tests in clinical assessment, stated that the highest satisfaction was obtained in the cognitive, emotional, and psychomotor domains using OSCE method.(35) TJE method has the same advantages as accuracy, validity and reliability, objectivity, non-interference of the instructor's luck and taste in the assessment process, therefore, it is recommended to use this method to assess the essential clinical skills of students such as clinical reasoning.

\section{CONCLUSIONS}

According to the results of this study, TJE, which is a method for assessment of learners' knowledge and skills in solving clinical problems and can be used in self-learning and problem-based curriculum more frequently, can be effective on the development of clinical reasoning of nursing students. In fact, clinical reasoning is a logical process for collecting key information points, understanding the patient's clinical problems and situations, planning and implementing, and evaluating interventions, and providing feedbacks. The majority of students of the experimental group was satisfied with this assessment method and also believed that the application of such method was innovative and excellent and an effective method of learning and assessment. Therefore, it is suggested that education administrators use problembased clinical methods so that qualified nursing graduates can be nurtured in the clinical assessment of learners.

\section{ACKNOWLEDGMENTS}

This research is extracted from a research project approved by Zabol University of Medical Sciences. The researchers would like to express their thanks to all the students who participated in this study.

\section{REFERENCES}

[1] Khatab AD, Rawlings B. Assessing nurse practitioner student using a modified objective structured clinical examination (OSCE). Nurse Education Today 2001;21(7):541-50. 
[2] Sand KJ. Evaluating the student clinical learning environment: development and validation of the SECEE inventory. Southern Online J Nursing Research 2000;1(4):2-4.

[3] Nahas VL, Nour V, Al-Nobani M. Jordanian undergraduate nursing students' perceptions of effective clinical teachers. Nurse Educ Today 1999;19(8):639-48.

[4] Salehi Sh. Compared the clinical teachers skills from the teachers and students opinions in Isfahan Medical University. Iran Med Education J 2004;11:35-41.

[5] Dugas B. Introduction to patient care. A comprehensives approach to nursing. $3^{\text {rd }}$ edn. New Zealand: Trade Me Ltd., 1987.

[6] Karimi P. Assessment and comparing the nursing students' opinion to the clinical teachers' characters on nursing and midwifery college of Gilan Medical Science University. J Tehran Nursing and Midwifery College 1996;5(18):30-3.

[7] Ghanbari A, Monfared A. Survey of clinical evaluation process based on logbook and cognitive and psychomotor learning in nursing students. Research in Medical Education 2014;6(2):28-35.

[8] Zareiedehbaghi F. Study of the quality of clinical evaluation with OSCE method for nursing students teaching in neonatal ward. J Faculty of Nursing \& Midwifery of Shaheed Beheshti Univ of Med Sci \& Health Serv 2001;11(38):10-5.

[9] Bagharpoosh M. Study of teachers evaluation of hamedan nursing and midwifery college clinical service. Proceeding of International Congress of the Quality of Nursing and Midwifery Works and Educations, Hamedan, Iran 2000 Nov 22-23.

[10] Hadizadeh F, Firoozi M, Razavi SN. Nursing and midwifery students' perspective on clinical education in Gonabad University of Medical Sciences. Iranian Journal of Medical Education 2005;5(1):70-8.

[11] Khosravi SH, Pazargadi M, Ashktorab T. Nursing students' viewpoints on challenges of student assessment in clinical settings: a qualitative study. Iranian Journal of Medical Education 2012;11(7):73549.

[12] Farokhi F, Khadivezade T. Common errors in evaluating the clinical performance of students of nursing and idwifery university of Mashhad in 2003 Abstract of 6th National Congress of Medical Education. Tehran: Shaheed Beheshti University of Medical Sciences 2003.

[13] Delaram M. Clinical education statue from the nursing midwifery students' opinions in Shahrekord Medical Science University. Iranian Medical Science Education J 2006;6(2):134-40.

[14] Khadivzade T, Farokhi F. The study of the strength and weak points of clinical education from nursing and midwifery students in Mashhad Medical Science University. Iranian Medical Science Education J. 2003;10:67.

[15] Imanipour M, Jalili M. Nursing students' clinical evaluation in students and teachers views. Nursing Research 2013;7(25):17-26.

[16] Grauer GF, Forrester SD, Shuman C, et al. Comparison of student performance after lecture-based and casebased/problem-based teaching in a large group. J Vet
Med Educ 2008;35(2):310-17.

[17] Latifi M, Shaban M, NikbakhtNasrabadi A, et al. Comparison of the effect of clinical evaluation by two methods: Portfolio and popular, on satisfaction of nurse students. Nursing Research 2012;6(21):15-28.

[18] Amin Z, Eng KH. Basics in medical education: World Scientific 2009. http://www.bio.ltsn.ac.uk/journal/vol5/BEEj-5R1.pdf

[19] Boud D, Feletti G. The challenge of problem-based learning. $1^{\text {st }}$ edn. Routledge 1998.

[20] Wood DF. ABC of learning and teaching in medicine: problem based learning. British Medical Journal 2003;326(7384):328-30.

[21] Newble D, Cannon RA. A handbook for medical teachers. Forth edition. International Journal of Gynecol Cancer 2003;13(1):101.

[22] Matthes J, Look A, Hahne AK, et al. The semi-structured triple jump-a new assessment tool reflects qualifications of tutors in a PBL course on basic pharmacology. Naunyn-Schmiedeberg's Archives of Pharmacology 2008;377(1):55-63.

[23] Banning M. Clinical reasoning and its application to nursing: concepts and research studies. Nurse Educ Pract 2008;8(3):177-83.

[24] Seidi J, Alhani F, Salsali M. Clinical judgment in nursing: a concept analysis using Rodgers' evolutionary method. Hyat Journal 2015;20(2):1-13.

[25] Kuiper RA, Pesut DJ. Promoting cognitive and metacognitive reflective reasoning skills in nursing practice: self-regulated learning theory. J Adv Nurs 2004;45(4):381-91.

[26] Mattingly C. What is clinical reasoning? Am J Occup Ther 1991;45(11):979-86.

[27] Levett-Jones T, Hoffman K, Dempsey J, et al. The 'five rights' of clinical reasoning: an educational model to enhance nursing students' ability to identify and manage clinically 'at risk' patients. Nurse Educ Today 2010;30(6):515-20.

[28] Seidi J, Alhani F, Salsali M, et al. Challenges of nurses' clinical judgment education: a qualitative study. Iranian J Nursing Research 2016;11(3):48-57.

[29] Lapkin S, Levett-Jones T, Bellchambers $H$, et al. Effectiveness of using human patient simulation manikins in the teaching clinical reasoning skills to undergraduate nursing students: a systematic review. Clinical Simulation in Nursing 2010;6(6):e207-e22.

[30] Hekmatipour N, Jooybari L, Sanagoo A. Can we use the "script concordance" test as a valid alternative method to evaluate clinical reasoning skills in nursing students? Iranian Journal of Medical Education 2017;17(40):3813.

[31] Habibi H, Khaghanizade M, Mahmoodi H, et al. Comparison of the effects of modern assessment methods (DOPS and Mini-CEX) with traditional method on nursing students' clinical skills: a randomized trial. Iranian Journal of Medical Education 2013;13(5):36472. 
[32] Salehi S, Safavi M, Mashoof S, et al. Effects of peer education on clinical skills in nursing students, including interns and trainees. Medical Sciences 2016;26(1):36-45.

[33] Hekmatpou D. Effect of portfolio based evaluation on accuracy of clinical evaluation of nursing students during internship in Arak University of Medical Sciences, Iran. Strides Dev Med Educ 2013;10(1):60-9.

[34] Sadeghi T, Shahabi M. Evaluation of nursing students using objective structured clinical examination: a strategy for assessing students' competence. Strides Dev Med Educ 2015;12(1):228-36.
[35] Bolourchifard F, Neishabory M, Ashketorab T, et al. Satisfaction of nursing students with two clinical evaluation methods: objective structured clinical examination (OSCE) and practical examination of clinical competence. Journal of Nursing \& Midwifery Shahid Beheshti 2009;19(66):38-42. 